\title{
A TROCA DE CARTÕES-POSTAIS COMO FERRAMENTA PEDAGÓGICA DE LEITURA E ESCRITA EM LÍNGUA INGLESA
}

\author{
Simone Tiemi Hashiguti* \\ Fabiane Lemes ${ }^{* *}$ \\ Rogério de Castro Ângelo**
}

RESUMO: No contexto do ensino regular, as aulas de Língua Inglesa voltam-se, não raro, principalmente para o trabalho com as habilidades de leitura e escrita, conforme promulgado pelos Parâmetros Curriculares Nacionais (PCNs). Contudo, a maior dificuldade enfrentada pelos professores é a de como motivar os alunos a engajarem-se efetivamente a participar de atividades de leitura e de escrita numa língua que não é aquela de suas interações cotidianas. Tal obstáculo advém principalmente de métodos de ensino que tomam a língua somente como objeto de gramática ou somente como instrumento de comunicação em situações artificiais, e que não a relacionam com práticas sociais que sejam ou se tornem significativas nos diferentes grupos e contextos de ensino. Neste trabalho, fazemos um relato de experiência de aplicação de uma sequência didática que visou à prática de escrita e leitura com cartões-postais. Baseando-nos no conceito bakhtiniano de gêneros textuais e em orientações epistemológicas do campo de estudos dos letramentos críticos, utilizamos o site Postcrossing para propor a estudantes de inglês como língua estrangeira (uma turma de nível básico e uma de intermediário) de um centro de idiomas, oferecido em um Instituto Federal, a lerem e escreverem cartões-postais para pessoas de diferentes países. Nosso objetivo foi averiguar se a atividade se constituiria como significativa para seus processos de aprendizagem de forma que houvesse engajamento, aprendizagem e posicionamento crítico de leitura.

PALAVRAS-CHAVE: Ensino de Língua Inglesa; Gêneros textuais; Cartão-postal; Colonialidade; Relações de poder.

\footnotetext{
* Professora Associada do Instituto de Letras e Linguística da Universidade Federal de Uberlândia (Ufu). Doutora e mestre em Linguística Aplicada pela Universidade Estadual de Campinas (Unicamp).

** Doutoranda em Estudos Linguísticos pela Universidade Federal de Uberlândia (Ufu). Mestre em Estudos Linguísticos pela Ufu.

${ }^{* * *}$ Mestre em Estudos Linguísticos pela Universidade Federal de Uberlândia (Ufu).
} 


\section{Introdução}

No contexto do ensino regular, as aulas de Língua Inglesa voltam-se, sobretudo, para o trabalho com as práticas de leitura e escrita. Mesmo com a ênfase nessas práticas em detrimento da compreensão e da produção oral, uma das dificuldades enfrentadas pelos professores é a de produzir ou encontrar materiais e atividades com as quais o alunado se identifique e nas quais se engaje efetivamente.

Nas turmas de inglês com as quais trabalhamos no interior do Estado de Minas Gerais, que contam com alunos de diferentes faixas etárias (o mais novo com 13 anos e a mais velha com 54 anos), percebemos certa passividade dos alunos no que se refere à prática de leitura e escrita para além daquilo que é oferecido no material didático escolhido pela instituição. Constantemente refletimos sobre formas de motivá-los a testarem seu crescimento na língua-alvo fazendo leitura de textos autênticos, produzidos por pessoas de diversas nacionalidades e que se utilizem da Língua Inglesa em práticas discursivas (sobretudo escritas), bem como formas de instigá-los a escreverem textos também autênticos, sobre si mesmos, em Língua Inglesa, que serão enviados para pessoas de diversas nacionalidades.

Entendemos que tal atividade, feita por meio da troca de cartões-postais, seja uma forma interessante de motivar os alunos a lerem e a escreverem em Língua Inglesa, estabelecendo um contato real com falantes de inglês do Brasil e de outros lugares do mundo. Nessa perspectiva, o presente trabalho visa a analisar como o trabalho com o site Postcros$\operatorname{sing} g^{22}$ pode se constituir como significativo para os processos de escrita e leitura em língua inglesa como língua estrangeira de nossos estudantes. Localizamos essa investigação dentro

\footnotetext{
22 < https://www.postcrossing.com/>. Trata-se de um site em que, após realizar um cadastro, você pode solicitar um endereço para enviar cartões postais para pessoas ao redor do mundo. Para cada cartão enviado, um cartão será enviado para o seu endereço, normalmente com uma mensagem em Língua Inglesa, sobre um tópico que o usuário tiver descrito no cadastro.
} 
do projeto de pesquisa Língua(gem) e/como acolhimento ${ }^{23}$, do qual participamos como pesquisadores.

Para tanto, filiamo-nos à Linguística Aplicada Crítica consoante à possibilidade de "hibridismo teórico metodológico" (FABRÍCIO, 2008), o que nos confere maior problematização crítica e expansão dos quadros interpretativos do corpus a ser analisado. Além disso, partimos dos estudos decoloniais e do conceito de cultura para entendermos questões que envolvem o ensino de línguas no Brasil, hoje, bem como as políticas relacionadas ao tema. No percurso teórico-metodológico, consideramos ainda certos preceitos da Análise do Discurso, que entende a língua não apenas como instrumento de comunicação, mas como parte constitutiva dos sujeitos (ORLANDI, 2012). Por conseguinte, tais conceitos, juntos, confluem na plausibilidade interpretativa das políticas linguísticas e nos ajudam a discutir as dificuldades enfrentadas pelo sujeito-aprendiz no que tange à Língua Inglesa. Além disso, subsidiam certa reflexão acerca da importância contextual no processo de ensino-aprendizagem enquanto fator que possa aumentar o afeto e a potência (DELEUZE; GUATTARI, 2003) de estudo e engajamento dos alunos na aprendizagem da língua.

Ademais, é importante ressaltar que mensuramos a aprendizagem de língua estrangeira como uma prática complexa, a qual provoca o sujeito a se deslocar em relação à sua possibilidade de enunciar. Nesse percurso, “[...] damos de encontro com fatos de linguagem que resultam da específica relação que esse sujeito, objeto do entremeio, vai travando ao se esbarrar com o real da língua, ao (ar)riscar na língua do outro” (CELADA, 2016, p. 28).

Dessa forma, pretendemos observar como o trabalho com os cartões-postais pode e poderá, em experiências futuras, servir de elemento que colocará os sujeitos-alunos em contato com a língua do outro, a fim de que eles também possam arriscar-se nessa língua outra, constituindo-se sujeitos dessa língua, de modo que a aprendizagem da Língua Inglesa ocorra de modo mais significativo.

\footnotetext{
${ }^{23}$ Projeto sob coordenação da Profa. Dra. Simone Tiemi Hashiguti, que está sendo desenvolvido na Universidade Federal de Uberlândia.
} 


\section{Desbravando caminhos no ensino de Língua Inglesa}

O contexto do ensino básico, no Brasil, é marcado pela heterogeneidade, o que inviabiliza métodos homogêneos de ensino, principalmente quando se trata de Língua Inglesa (doravante LI). Apesar disso, grande parte dos materiais didáticos voltados para a prática de LI apresentam metodologias ultrapassadas, que não levam em consideração o contexto dentro e fora da sala de aula, isto é, a individualidade dos alunos e a conjuntura social e histórica em que estão imersos, as quais se encontram em constante transformação.

Umas das justificativas para essa linearidade metodológica pode ser relacionada aos preceitos decoloniais, pois, conforme o filósofo Maldonado-Torres,

a colonialidade do saber-poder se mantém viva em manuais de aprendizagem, nos critérios para o bom trabalho acadêmico, na cultura, no senso comum, na autoimagem dos povos, nas aspirações dos sujeitos e em muitos outros aspectos de nossa experiência moderna. Neste sentido, respiramos a colonialidade na modernidade cotidianamente. (2007, p. 131)

A herança do saber-poder consolidou métodos ineficazes, infensos a mudanças de perspectiva no que tange ao ensino-aprendizagem de línguas. Portanto, é preciso pensar novas epistemologias no intuito de abarcar a heterogeneidade presente no universo escolar, desmistificando estratificações intelectuais.

Os estudos decoloniais surgem como uma tentativa de reflexão crítica que supere o conhecimento universal posto pelo eurocentrismo e os denominados países do norte, também chamados colonizadores. Nessa perspectiva, ainda que países colonizados, como o Brasil, tenham se tornado independentes em dado momento da história, as formas de saber-poder, bem como questões culturais, permaneceram (SILVA; PROCÓPIO, 2019).

Além disso, entre as características da colonização está o apagamento do "outro", em razão da necessidade de definir-se colonizador e colonizado. Não à toa trazemos esse mote para nossa discussão, pois entre as grandes dificuldades no ensino de LI, no caso do Brasil, está a dependência histórica das forças centralizadoras oriundas da política e da economia europeias. Como consequência, cabe ao subalterno o silêncio, pois há quem fale por 
ele (SPIVAK, 2010). Logo, a tomada da palavra em língua inglesa e o interesse, em si, pela língua são perversos desafios enfrentados pela imensa maioria de brasileiros no contexto de ensino-aprendizagem.

Ademais, o apagamento desse "outro", que se encontra num entre-lugar (BHABHA, 1998) de exclusão, é fruto do que Foucault (1995) denomina como relações de poder, responsáveis por legitimar saberes que culminam na normatização de certas práticas e na discriminação de outras. Assim, as práticas relacionadas ao ensino de línguas, particularmente de LI, por ser o nosso foco, são cenário de políticas linguísticas, as quais abrangem "uma vasta gama de atividades que vão desde as políticas locais ou pontuais que envolvem o uso da língua às políticas mais complexas e organizadas pelas autoridades governamentais" (RAJAGOPALAN, 2011, p. 126-127).

Isso posto, todas essas atividades são atravessadas pelas relações de poder, uma vez que são erigidas mediante conflitos ideológicos que envolvem constantes disputas de diferentes grupos (órgão governamentais, pesquisadores, etc.) pelo saber-poder (Foucault, 1988), os quais ditam o tom das políticas educacionais e linguísticas. Como resultado desse embate, surgem diferentes perspectivas epistemológicas que amparam o ensino de línguas, materializadas por documentos como os Parâmetros Curriculares Nacionais (PCNs), os quais estabelecem diretrizes cujo foco está na orientação do trabalho docente, dando direção às atividades abordadas na sala de aula.

No que se refere ao ensino de Língua Estrangeira no Ensino Fundamental, os PCNs já direcionavam, em 1998, o trabalho voltado sobretudo para a leitura e escrita de textos, o que explica nossa escolha por trabalhar com cartões-postais. Por conseguinte, os PCNs justificam a ênfase no trabalho com a leitura em LI a partir da demanda que se tem no contexto escolar e nos processos avaliativos cujos objetivos sejam a inserção do aluno em cursos de graduação. Ademais, a habilidade de leitura também é vista pelo documento como principal preceito relacionado ao espaço escolar, pois além de contribuir para o desenvolvimento do aluno, corrobora a formação inclusive na língua materna. 
De acordo com Orlandi,

[...] a leitura é o momento crítico da constituição do texto, o momento privilegiado do processo de interação verbal, uma vez que é nele que se desencadeia o processo de significação. No momento em que se realiza o processo da leitura, se configura o espaço da discursividade em que se instaura um modo de significação específico. (ORLANDI, 2012, p. 49)

Nessa conjuntura, a leitura é um processo discursivo que é produzido num contexto sociohistórico, no qual o leitor não apreende meramente um sentido, ele atribui sentidos ao texto. Durante esse processo, é fundamental que haja uma interação entre texto e leitor, o que podemos entender da seguinte forma:

Para melhor explicar esse processo de interação entre leitor e texto, vamos fazer uma analogia entre o processo da leitura e uma reação química. Na leitura, como na química, para termos uma reação é necessário levar em conta não só os elementos envolvidos, mas também as condições necessárias para que a reação ocorra. O simples confronto do leitor com o texto não garante a eclosão de todos os acontecimentos que caracterizam o ato da leitura. A produção de uma nova substância - no caso a compreensão - só ocorre se houver afinidade entre os elementos leitor e texto e se determinadas condições estiverem presentes. (LEFFA, 1996, p. 14)

Nesse sentido, buscamos compreender como o trabalho com cartões-postais pode propiciar momentos de leitura que levem os alunos à compreensão, de fato, das mensagens que lhes forem direcionadas.

Além disso, os PCNs ressaltam a importância de, no contexto de ensino-aprendizagem, avançar a um patamar que exceda as questões gramaticais, equívoco constantemente cometido por inúmeros professores de LI. É fundamental, além do conhecimento do vocabulário e das regras gramaticais, o uso efetivo da língua, isto é, a língua em uso, que é justamente o que propomos neste trabalho com o gênero cartão-postal.

Acerca disso, os PCNs asseveram que o conhecimento da língua deve ser atrelado ao seu uso imediato. Tal preceito advém da necessidade de relacionar o que se aprende na 
escola a circunstâncias sociais ou, em outras palavras, de unir teoria e prática num processo que se reflete na formação cidadã do sujeito aprendiz. É preciso, portanto, que haja compreensão teórica do que é a linguagem, tanto do ponto de vista dos conhecimentos necessários para usá-la quanto em relação ao uso que se faz desses conhecimentos para construir significados no mundo social (BRASIL, 2000, p. 29).

Ainda nessa perspectiva, os PCN+, voltados ao Ensino Médio, discutem a necessidade de os alunos se inscreverem na língua em "situações da vida cotidiana". Ora, uma vez que vivemos em um país em que não se utiliza tão frequentemente a Língua Inglesa em situações reais de interação, consideramos que o trabalho com correspondências, oportunizado pelo uso de cartões-postais, inscreve-se como uma alternativa possível para essas práticas da/na língua estrangeira de forma concreta. Nos $\mathrm{PCN}+$, temos que:

O caráter prático do ensino da língua estrangeira permite a produção de informação e o acesso a ela, o fazer e o buscar autônomos, o diálogo e a partilha com semelhantes e diferentes. Para isso, o foco do aprendizado deve centrar-se na função comunicativa por excelência, visando prioritariamente a leitura e a compreensão de textos verbais orais e escritos - portanto, a comunicação em diferentes situações da vida cotidiana.[...] $\mathrm{Na}$ vida escolar, no mundo social e do trabalho o jovem deverá confrontar-se com desafios que só poderão ser resolvidos no âmbito prático mediante o acesso à informação e à mobilização seletiva de competências e habilidades apropriadas (aprender a conhecer e aprender a fazer). (BRASIL, 2007, p. 94)

Indubitavelmente, os PCN+ reforçam o caráter prático do ensino de LI como característica indispensável para um ensino-aprendizagem eficaz. Ao apontar a imprescindibilidade da relação entre o que se aprende e as vivências do aluno, pelo intermédio da LI, perceber o espaço da enunciação, o contexto, torna-se indispensável.

Outrossim, nas Orientações Curriculares para Ensino Médio, especificamente no que se refere ao ensino de línguas estrangeiras, salienta-se a importância contextual para o LC, haja vista a imprescindibilidade de acionar diferentes conhecimentos do aluno na busca por sentidos, estabelecidos além da superfície textual.(MONTE MOR; SOUZA, 2006) 
Logo, ao trabalhar-se com o exterior, valores globais são colocados em prática na sala na aula. Do mesmo modo, considerar as implicações individuais faz parte desse roteiro e contribui para o engajamento do sujeito aprendiz, o qual não apenas estabelecerá um elo entre teoria e prática, mas se identificará cerne desse processo.

Ainda assim, contemplar a diversidade imprime imensa complexidade às escolas e aos professores, os quais precisam encontrar meios de adaptar práticas de ensino, de forma a se tornarem efetivas. Logo, o Letramento Crítico (LC) e as sequências didáticas, num trabalho conjunto com os gêneros discursivos, tornam-se importantes ferramentas motivacionais de aprendizagem.

O LC é uma forma de dar autonomia ao professor, possibilitando o "espaço criativo, sensível aos contextos locais e globais, resistente a pensamentos únicos [...], totalizadores e inibidores de ações que considerem a contingencialidade dos espaços de enunciação" (FOGAÇA et al., 2007, p. 189). No LC, portanto, deve haver constante reflexividade, isto é, ver-se atravessado pelo outro e ressignificado por espaços outros, a fim de que essa perspectiva não seja banalizada.

Concomitantemente à relevância de considerar-se a contingencialidade do espaço, além da importância da liberdade criativa, conforme propõe o LC, enfatizamos o papel dos gêneros do discurso nesse percurso metodológico do ensino de LI, no nosso caso o cartãopostal. De acordo com Bakhtin (2003), todos os campos da atividade humana estão ligados ao uso da linguagem. Nesse sentido, a língua é empregada a partir de enunciados, os quais refletem condições específicas. Embora cada enunciado seja individual, as condições de produção determinam tipos relativamente estáveis de enunciados, denominados gêneros discursivos. Dessa forma, os gêneros do discurso são heterogêneos devido à sua característica multiforme, além de possuírem intrínseca relação com o contexto.

Ao propormos a troca de mensagens como ferramenta metodológica para o trabalho com LI, sobretudo técnicas de leitura e escrita, foco deste trabalho, fazemo-lo pensando em estratégias capazes de motivar o aluno. A partir disso, associamos a teoria à prática quando o aluno se torna copartícipe do processo de ensino-aprendizagem, o que é feito 
mediante a troca de cartões-postais entre usuários do site postcrossing. Por se tratar de uma ferramenta tecnológica, o aluno pode comunicar-se com pessoas do mundo todo.

Além disso, consideramos o lugar de fala desses sujeitos de linguagem, isto é, o contexto cultural, pois, a princípio, sugere-se que o remetente escreva sobre a sua cidade, destacando suas opiniões acerca das características locais, o que amplia o interesse e, consequentemente, o engajamento do aluno.

Ao se falar sobre a importância contextual e de se olhar para o local que o outro ocupa no ensino de LI, emerge a importância da cultura, entendida por Bhabha (1998) pela vertente heterogênea, ao contrário de diversos estudos que se apropriaram do conceito como algo indiscutivelmente homogêneo. A respeito disso, Souza (2010) parte do princípio de que ao se estabelecer uma universalização cultural, instituem-se também dogmas cujos princípios são categorizadores. Nessa perspectiva, universalizar seria excluir as diferenças, apagando, portanto, as marcas da alteridade.

Isso posto, universalizar, aqui, pode ser entendido sob dois aspectos, ambos abrangendo a LI: a) o primeiro estaria ligado à denominação da LI como língua universal devido ao seu alcance mundial; b) o segundo se refere à homogeneização das formas de ensino. Poderíamos, é claro, ressaltar outras questões no que tange à universalização, como a pronúncia, porém delimitamos nossa discussão a partir de nosso corpus.

Diante dos desafios relacionados à universalização do ensino de LI, surge a necessidade de trabalhar-se com métodos diferenciados com o intuito de afetar do sujeito aprendiz. É-nos caro ressaltar, ainda, que compreendemos o afeto e a potência numa perspectiva rizomática (DELEUZE; GUATTARI, 2003) de pensar e existir.Por afeto, entendemos a habilidade de afetar e ser afetado, ambos oriundos da proposição espinozana sobre os termos do latim "affectus" e "affectio", afeto e afecção, respectivamente. Nessa perspectiva, o sentido de afecção se remete "ao estado do corpo afetado e implica a presença do corpo afetante, ao passo que o afeto remete à transição de um estado a outro, tendo em conta variação correlativa dos corpos afetantes" (DELEUZE, 2002, p. 56). Por conseguinte, de acordo com Deleuze \& Guattari (2003), o afeto coordena como o pesquisador se situa 
frente ao seu objeto de pesquisa, o que nos posiciona, metodologicamente, à concepção cartográfica de pesquisa. Logo, cartografar um estudo é “dar língua para os afetos que pedem passagem” (ROLNIK, 2014, p. 23), é dar lugar às intensidades que mobilizam pesquisador e pesquisado.

Assim sendo, propomo-nos a averiguar se, e de que maneira, os alunos são afetados pela metodologia proposta, de forma a terem sua potência de agir elevada, o que culmina no engajamento em relação às práticas de leitura e escrita na sala de aula. Entendemos que a potência é um processo em variação, o qual pode ser positivo ou negativo a depender do afeto e da intensidade do afeto que sofre o sujeito. Ser afetado em uma prática de sala de aula significa, portanto, sair da indiferença frente a um tema, assunto ou processo de produção de sentido. Estar com a potência elevada para uma prática ou processo de aprendizagem é, por sua vez, estar aberto e propenso à experiência de aprender.

\section{Sequência didática do gênero cartão-postal}

Neste trabalho, buscamos trabalhar o gênero cartão-postal contemplando os três elementos essenciais, tal como defendido por Bakhtin (2016), a saber: o conteúdo temático, o estilo e a construção composicional. Para tal, organizamos nosso trabalho em forma de uma sequência didático, tendo como horizonte as discussões sobre Letramento Crítico.

\section{$1^{\circ}$ momento - explorando o gênero.}

Visando à familiarização dos alunos com o gênero, o professor levou para a sala de aula uma caixa com diversos cartões-postais recebidos de diferentes lugares.

Inicialmente, o professor distribuiu os cartões entre os alunos, que deveriam observar as diferenças e semelhanças entre eles. Em seguida, o professor iniciou uma discussão oral visando a discutir com os alunos em relação à estrutura composicional, ao estilo e ao conteúdo temático do gênero. Para isso, o professor levantou as seguintes questões: 
a) Que tipo de imagens aparecem nos cartões-postais? As paisagens, animais, pinturas, etc. se parecem com as quais você conhece?

b) Que tipo de imagem não aparecem nos cartões-postais?

c) De onde os cartões vieram?

d) Há algum texto escrito? A mensagem é longa ou curta?

e) Que sentido(s) você consegue construir para as mensagens nos cartões?

f) Que tipo de informação há na mensagem?

g) A mensagem tem um tom mais formal ou informal?

h) Que tipo de informação sobre o destinatário há no cartão?

i) Que tipo de informação sobre o remetente há no cartão?

j) Quanto custa enviar um cartão para esses lugares?

k) Para que servem os selos? Que tipo de selos há nos cartões? Quantos selos são necessários para enviar um cartão para outro país?

1) Por que as pessoas enviam/trocam cartões-postais?

Com base em tais perguntas, buscou-se construir sentidos além da superfície textual, a partir do conhecimento de mundo dos próprios alunos, conforme a perspectiva do LC. Para tanto, os contextos histórico, cultural e social foram acionados mediante inferências, com intermédio do professor, dos próprios alunos, o que resultou em uma experiência multicultural cujo intuito pautou-se no desenvolvimento da consciência crítica (MONTE MOR; SOUZA, 2006).

\section{$2^{\circ}$ momento - explorando o site Postcrossing}

Em outra aula, o professor apresentou aos alunos o site "postcrossing.com" e explicou que ele permite a troca de cartões-postais entre pessoas que moram em diferentes lugares do mundo.

Na página inicial do site, temos a tela inicial, representada na Figura 1: 
Figura 1: Tela inicial do site Postcrossing.com.

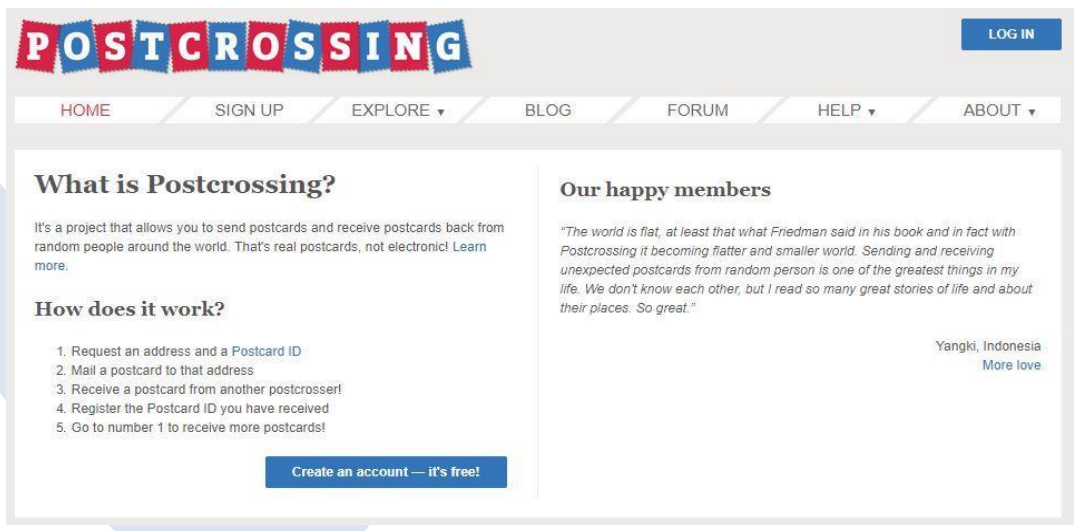

Fonte: os autores.

Para que essa troca ocorra, primeiramente deve-se fazer um cadastro no site. Há a possibilidade de criar uma conta de grupo ou individual. No caso da turma, foi feita uma conta para a turma toda, de forma que um dos alunos foi fornecendo os dados para o preenchimento do cadastro, com a ajuda dos colegas e do professor.

A tela de cadastro pode ser visualizada na Figura 2:

Figura 2: Tela de cadastro no site postcrossing.com

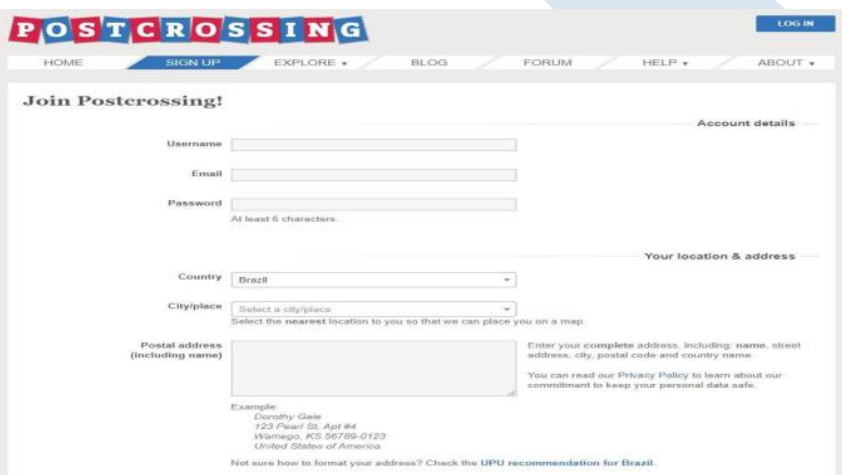

Fonte: os autores. 
Para o cadastro, os alunos criaram um nome de usuário para a turma, forneceram o e-mail da turma (que eles já haviam criado para a troca de arquivos da disciplina) e criaram uma senha. Para o endereço, foi fornecido o endereço da escola, com indicação da turma e o respectivo ano.

Uma vez feito o cadastro, há basicamente quatro passos a serem seguidos:

1. Solicitar um endereço e um ID $^{24}$ do cartão-postal.

2. Escrever um cartão para a pessoa "sorteada" e postar no correio.

3. Receber um cartão de outro usuário do site.

4. Registrar o ID do cartão recebido.

Para solicitar o endereço para onde seriam enviados os cartões, os alunos foram divididos em cinco grupos, fizeram o login na plataforma e solicitaram o endereço para onde teriam que enviar o cartão-postal. Fazendo isso, o site abre uma tela com o nome, endereço e um perfil do usuário para quem eles enviariam o cartão-postal. Além disso, essas informações são enviadas para o e-mail da turma, facilitando a recuperação dessas informações.

Depois que cada grupo solicitou um endereço para enviar os cartões, o professor acessou o e-mail da turma e fez um trabalho com os alunos de exploração do "perfil" dos destinatários para os quais seriam mandados os cartões. No site em questão, geralmente o perfil dos usuários traz uma breve apresentação pessoal (idade, nacionalidade, estado civil) e então são descritos os tipos de imagens que a pessoa gostaria de receber nos cartõespostais, bem como alguma sugestão de tema para a mensagem que será escrita).

Depois de explorar em grupo os perfis dos usuários, os alunos montaram, coletivamente, um perfil da turma, com a descrição da faixa etária da turma, além da descrição de

\footnotetext{
${ }^{24} \mathrm{O}$ site gera um número de ID para cada cartão, de forma que, ao receber o cartão-postal, o destinatário insere o número na plataforma e pode escrever uma mensagem de agradecimento ao remetente. Quando isso ocorre o sistema envia um e-mail confirmando que o cartão chegou ao destino e libera o remetente para receber um cartão de outro usuário, aleatoriamente.
} 
quais tipos de cartões e de que tipo de assunto gostariam de receber nos cartões, e cadastraram esse perfil no site.

Consideramos este momento de discussão sobre o perfil dos nossos destinatários, que vivem em outros lugares do mundo, um momento importante para discutir sobre as características culturais dos nossos interlocutores. Nessa discussão, fez-se necessário levar em conta as discussões sobre cultura, de forma a criar um ambiente em que os alunos percebam o outro como alguém inscrito numa cultura diferente, mas não num lugar de submissão em relação aos "do Norte", de forma a propiciar um ambiente que favorecesse a tomada da palavra.

\section{$3^{\circ}$ momento - primeira versão dos cartões}

Novamente agrupados nos cinco grupos, os alunos precisam retomar o perfil do destinatário para decidirem qual imagem enviarão bem como o que o destinatário solicitou como tema da mensagem.

Frequentemente os usuários solicitam alguma paisagem, animal, pintura ou comida típica do local de origem do remetente. Dessa forma, o professor estimula os alunos a pensarem em qual imagem melhor representaria a cultura local (da cidade ou da região), mas mantendo como horizonte as discussões sobre cultura de Bhabha (1998), que ressalta a importância de não pensar em uma homogeneização em meio a uma mesma cultura.

Em relação à mensagem, o professor deixou com cada grupo alguns cartões para que eles pudessem tomar de modelo para rascunharem, ainda no caderno, uma mensagem de apresentação do grupo, de descrição da imagem que eles haviam selecionado, além de responderem a eventuais curiosidades constantes na mensagem do perfil do destinatário.

Como não há muitas opções de cartões-postais pré-fabricados da cidade onde moramos, após a escolha dos grupos, eles ficaram com a incumbência de tirar uma foto ou selecionar uma imagem na internet para a composição da parte da frente do cartão-postal. A imagem deveria ser enviada para o e-mail do professor, para ser providenciada a impressão dos cartões. 


\section{$4^{\circ}$ momento - revisão do texto e confecção da versão final}

O professor providenciou a impressão das imagens enviadas pelos grupos e, para a confecção da versão final dos cartões, deu orientações de eventuais correções na primeira versão do texto que havia sido escrito. Além disso, os alunos foram orientados sobre o local e a ordem do preenchimento das informações sobre o destinatário, bem como onde registar o ID do cartão. Em seguida os cartões foram entregues na secretaria da escola, para serem selados e enviados.

\section{$5^{\circ}$ momento - discussão dos cartões e e-mails recebidos}

Quando os cartões chegaram aos destinatários, eles registraram os cartões no site e recebemos os e-mails confirmando o recebimento. O professor abriu o e-mail da turma na sala e fizemos a leitura e discussão das mensagens. Neste momento, os alunos ficaram satisfeitos em ter um feedback dos destinatários, sobretudo devido ao fato de perceberem como o trabalho havia se mostrado uma situação instigante de valer-se da LI para conhecerem pessoas de outras nacionalidades.

Duas semanas depois, recebemos os cartões-postais de outros cinco usuários do site. Então, o professor abriu o site para que os alunos pudessem registrar os cartões e, coletivamente, escreverem uma mensagem de agradecimento para os remetentes, de acordo com o que havia sido enviado em cada cartão.

\section{Postcrossing e os afetos}

Ao longo do trabalho com cartões-postais, foi possível perceber o aumento da potência de agir dos alunos mediante o engajamento e a disposição que eles tiveram durante toda a prática pedagógica com a ferramenta Postcrossing.Tal recorrência foi percebida justamente pelas reações dos corpos afetados, isto é, atravessados por afetos, dos quais resultaram determinados gestos e comportamentos, os quais nos permitiram chegar a essa análise.

Primeiramente, notamos a empolgação dos alunos no que se refere ao gênero trabalhado. De acordo com alguns deles, inclusive, o imediatismo das relações modernas, 
possibilitado pelas novas tecnologias, faz com que as pessoas não deem tanto valor às formas de comunicação. Nesse sentido, a efemeridade das relações sociais foi posta pelos alunos como algo negativo, uma vez que tudo parece ser descartável. Logo, o fato de esperar por uma correspondência mostrou-se nessas aulas, especificamente, como fator cativante aos alunos, pois a espera da resposta aos cartões enviados por eles causou excitação na turma, como um todo.

Além disso, os alunos mais novos ficaram maravilhados com a ferramenta trabalhada. A entonação da voz e a disposição de todos para a referida prática de ensino mostrou claramente o quanto eles estavam sendo afetados positivamente pelo método. Numa das turmas, uma das pessoas que enviou cartões-postais para a turma, em vez de mandar um cartão para a turma toda, que era o esperado, enviou um cartão direcionado a cada um dos estudantes, cada um com uma curiosidade sobre a região onde ela mora, tais como montanhas, túneis, alguns animais e atrações turísticas, o que causou grande euforia, vista em seus sorrisos, suas expressões faciais e na empolgação em mostrar uns para os outros a correspondência que veio de tão longe, destinada especificamente a eles.

Notamos que tais demonstrações de afeto realmente fizeram com que eles se sentissem pessoas importantes. Por conseguinte, esses alunos ficaram, visivelmente, comovidos com o carinho dos correspondentes, os quais demonstraram afeição ao compartilharem parte de suas experiências de vida, rotinas, cidades. Como resultado, tal afeto provocou nos alunos reciprocidade, trazendo o desejo do diálogo e da proximidade com o outro. Tivemos, assim, afeto e afecção trabalhando conjuntamente, e produtivamente, nas práticas de ensino de LI.

\section{Considerações finais}

O engajamento dos alunos durante as atividades propostas nos permite afirmar que a sequência didática de leitura e escrita de cartões-postais, apresentada neste trabalho, é uma proposta interessante para se trabalhar o letramento crítico dos alunos em Língua Inglesa. Pudemos observar basicamente duas formas de afeto ao longo das atividades dessa 
sequência. A primeira é demonstrada por muitos dos alunos mais velhos, que foram afetados positivamente (tendo um aumento da potência de agir) relatando uma certa nostalgia dos tempos em que a comunicação era feita principalmente por meio de cartas e cartõespostais, que têm sido substituídos por mensagens instantâneas. A segunda forma de afeto (também positivo) abarca os alunos mais novos, os quais, em sua maioria, envolveram-se nas atividades significando esse trabalho com cartões-postais como uma "novidade", muitos, inclusive, afirmando nunca terem enviado ou recebido cartões-postais anteriormente.

Além disso, percebemos um certo deslumbramento dos alunos em relação ao fato de corresponderem-se não apenas virtualmente, com pessoas de outras nacionalidades, mas valendo-se de uma materialidade diferente das mídias sociais.

Esta sequência didática contribuiu abrindo espaço para trocas culturais com pessoas de outros lugares, sem deixar de valorizar o que é local. Nesse sentido, acreditamos ter aberto espaços para que os alunos produzissem sentidos em Língua Inglesa.

Outrossim, esta sequência didática alinha-se às orientações constantes nos PCNs, PCN+ e nas Orientações Curriculares para o Ensino Médio, na medida em que o gênero cartão-postal foi trabalhado partindo de textos de circulação real e não focando apenas em questões estruturais ou gramaticais, mas sim numa formação cidadã pautada em situações concretas de comunicação.

Ademais, buscamos explorar questões relacionadas aos três elementos do gênero discursivo trabalhado, a saber: conteúdo temático, estrutura composicional e estilo (Bakhtin, 2016), além de discutirmos questões referentes às condições de produção que estão diretamente relacionadas à circulação social desse gênero.

Por fim, consideramos que este trabalho com os cartões-postais seja uma prática que interfere diretamente na potência de agir dos alunos, por meio do afeto que, nesse caso, resultou no engajamento dos alunos. Nesse sentido, a leitura e a escrita em Língua Inglesa, por meio de cartões-postais proporcionou um espaço que os instigou a estabelecerem um contato com o "outro", inscrevendo-se na língua do "outro", mas sem perder de vista o local. 


\title{
EXCHANGING POSTCARDS AS A PEDAGOGICAL TOOL FOR READING AND WRITING IN THE ENGLISH LANGUAGE
}

\begin{abstract}
In the context of regular education, English language classes often focus mainly on working with reading and writing skills, as promulgated by the National Curricular Parameters (PCNs). However, the biggest difficulty teachers face is how to motivate students to effectively engage in reading and writing activities in a language other than the one they use in their everyday interactions. This obstacle comes mainly from teaching methods that take language only as an object of grammar or only as an instrument of communication in artificial situations, and which do not relate it to social practices that are or become meaningful in different teaching groups and contexts. In this paper, we present an experience report of applying a didactic sequence aimed at practicing writing and reading with postcards. Based on the Bakhtinian concept of textual genres and epistemological orientations from the field of critical literacy studies, we use the Postcrossing website to propose, for students of English as a foreign language (a beginner group and an intermediate group) from a language center, offered at a Federal Institute, to exchange postcards with people from different countries. Our goal was to find out if the activity would be significant for their learning processes so that there was engagement, learning and critical reading positioning.
\end{abstract}

KEYWORDS: English Language Teaching; Textual genres; Postcard; Coloniality; Power relations.

\section{REFERÊNCIAS}

BAKHTIN, M. Estética da criaşão verbal. Trad. Paulo Bezerra. São Paulo: Martins Fontes, 2003.

. Os gêneros do discurso. Trad. Paulo Bezerra. São Paulo: Editora 34, 2016.

BHABHA, Homi. K, O local da cultura. Trad. Myrian Ávila, Eliana Lourenço de Lima Reis e Gláucia Renate Gonçalves. Belo Horizonte: Editora UFMG, 1998. p. 19-128.

BRASIL. Secretaria de Educação Fundamental. Parâmetros curriculares nacionais: terceiro e quarto ciclos do ensino fundamental: língua estrangeira / Secretaria de Educação Fundamental. Brasília : MEC/SEF, 1998. Disponível em: <http://portal.mec.gov.br/seb/arquivos/pdf/pcn_estrangeira.pdf>. Acesso em: 25 set. 2018.

BRASIL, Secretaria de Educação Ensino Médio - Parâmetros Curriculares Nacionais - Parte II: Linguagens, códigos e suas tecnologias. MEC: 2000. Disponível em: <http://portal.mec.gov.br/seb/arquivos/pdf/14_24.pdf >. Acesso em: 25 set. 2018.

BRASIL, Secretaria de Educação Ensino Médio. PCN + Ensino Médio: Orientações Complementares aos Parâmetros Curriculares Nacionais.Linguagens, Códigos e suas Tecnologias. MEC: 2007. Disponível em: <http://portal.mec.gov.br/seb/arquivos/pdf/linguagens02.pdf>. Acesso em: 25 set. 2018. 
DELEUZE, Gilles. Espinosa: filosofia prática. Trad. Daniel Lins e Fabien Pascal Lins. São Paulo: Escuta, 2002.

DELEUZE, Gilles; GUAT'TARI, Félix. A Thousand Plateaus: capitalism and schizophrenia. Tradução de Brian Massumi. Minneapolis/Londres: University of Minnesota Press, 2003.

FABRÍCIO, Branca Falabella. Linguística Aplicada como espaço de desaprendizagem: redescrições em curso. In: MOITA LOPES, L. P. (Org.). Por uma Linguística Aplicada indisciplinar. 2. ed. São Paulo: Parábola. 2008. p. 45-65.

FOGAÇA, F. et al. Entrevista com Clarissa Jordão. In: Revista X, vol. 12, n. 1. 2017. p. 187- 194.

FOUCAULT, M.História da sexualidade I: A vontade de saber. Trad. de Maria Thereza da Costa Albuquerque e lorlandi J. A. Guilhon Albuquerque. Rio de Janeiro, Edições Graal, 1988.

. O sujeito e o poder. In: RABINOW, P.; DREYFUS, H. Michel Foucault, uma trajetória filosófica: para além do estruturalismo e da bermenêutica. Rio de Janeiro: Forense Universitária, 1995.

(1970) A ordem do discurso. Aula inaugural no Collège de France, pronunciada em 1970. Trad. Laura Fraga de Almeida Sampaio. 5. Ed. São Paulo. Edições Loyola. 1996.

LEFFA, V. J. (1996). Aspectos da leitura. Porto Alegre: Sagra DC Luzzatto.

MALDONADO-TORRES, N. Sobre la colonialidad del ser: contribuciones al desarrollo de un concepto. In: CASTRO-GÓMEZ, Santiago; GROSFOGUEL, Ramón. (Orgs.). El giro decolonial. Reflexiones para una diversidad epistémica más allá del capitalismo global. Bogotá: Universidad Javeriana-Instituto Pensar/Universidad CentralIESCO/Siglo del Hombre Editores, 2007, p. 127-167.

MONTE MOR, W.; SOUZA, L. M. M. de. Orientações Curriculares para o Ensino Médio: Línguas Estrangeiras. In: Secretaria da Educação Básica. (Org.). Linguagens, Códigos e Suas Tecnologias. Brasília: MEC-SEB, 2006, v. 1, p. 85-124.

ORLANDI, E. P. Discurso e Leitura. 9 ed. São Paulo: Cortez, 2012.

RAJAGOPALAN, K. A norma linguística do ponto de vista da política linguística. In: LAGARES, X. C.; BAGNO, M. (Org.). Políticas da norma e conflitos linguísticos.

São Paulo: Parábola Editorial, 2011. p. 121-128.

ROLNIK, S. Cartografia sentimental: transformações contemporâneas do desejo. $2^{a}$ edição. Porto Alegre: Sulina; Editora de UFRGS, 2014.

SILVA, F. A.; PROCÓPIO, C. E. P. - Colonialidades do crer, do saber e do sentir: apontamentos para um debate epistemológico a partir do Sul e com o Sul. In: Revista de Ciências Sociais. Fortaleza, v. 50, n. 2, jul./out., 2019, p. 15-30. 
SOUZA, L. M. T. M. de. Cultura, língua e emergência dialógica. In: Letras \& Letras, Volume 26 - N. 2, jul.-dez., 2010, p. 289-306.

SPIVAK, G. C. Pode o subalterno falar? Belo Horizonte: Editora da UFMG, 2010.

Recebido em: 01/09/2019.

Aprovado em: 30/10/2019. 